\title{
An alternative approach to railway asset management value analysis: application to a UK raillway corridor
}

Jack Litherland BSc, PhD

Research Fellow, Resilience Engineering Research Group, University of Nottingham, Nottingham, UK (Orcid:0000-0002-6805-8765)

Gareth Calvert BSC, MSC

PhD student, Resilience Engineering Research Group, University of Nottingham, Nottingham, UK (Orcid:0000-0002-3453-4583)

\author{
John Andrews BSC, PhD, CEng \\ Professor, Resilience Engineering Research Group, University of \\ Nottingham, Nottingham, UK (corresponding author: \\ john.andrews@nottingham.ac.uk) \\ Sunny Modhara BSC, PhD \\ Whole Lifecycle Costing Manager, Technical Authority, Network Rail, \\ Milton Keynes, UK \\ Andy Kirwan BSC, MBA, PhD \\ Head of Advanced Analytics, Technical Authority, Network Rail, UK
}

\begin{abstract}
Railway networks are complex systems, and the management of such systems is a challenging task for railway asset managers. It is their responsibility to ensure that the network delivers the highest level of performance for all stakeholders while adhering to strict safety regulations and financial constraints. Historically, reliability, availability, maintainability and safety (RAMS) analysis has been used to assess the performance and safety of railway networks. Nonetheless, there is a lack of consistency in approaches across the industry, with analysis often influenced by the key stakeholders at the time. This research demonstrates an application of an extended RAMS (ExRAMS) framework on the UK railway network. The ExRAMS framework aims to consolidate various extensions to the traditional RAMS approach into a single universal approach, which is beneficial to all stakeholders. This paper explores the data currently available within the rail industry and how these can be used to assess the ten metrics within the framework. The final part of the paper explores how the parameters within the ExRAMS framework can be used as the bases of a value analysis, which can then be used to assist with asset-management decisions.
\end{abstract}

\section{Notation \\ $C_{i} \quad$ fatalities and weighted injuries consequence of $E_{i}$ \\ $E_{i} \quad i$ th hazardous event \\ $\alpha_{i} \quad$ scaling factor for $E_{i}$}

\section{Introduction}

Effective railway transport is key to the social and economic prosperity of the areas it serves, allowing mass, rapid transport of passengers and goods. Railway networks contain a diverse range of interconnected assets and a complex mixture of stakeholders. Competent management of the network is essential, as unreliable railways, with poor performance, quickly become unattractive to customers and businesses. Railway networks have many stakeholders, each having their own needs and requirements, which they assess using different metrics and benchmarks.

Traditionally, asset management has been based around balancing costs using cost analysis techniques (Srinivasan and Parlikad, 2017). These techniques include whole-life-cycle cost analysis (Fabrycky and Blanchard, 1991; Farr and Faber, 2018; Vandoorne and Gräbe, 2018) and reliability, maintainability and availability analysis (BSI, 2017; Mahboob and Zio, 2018). However, these traditional approaches often fail to capture all the parameters that are of interest to railway asset managers and by considering cost alone, fail to capture all the stakeholder requirements and hence do not deliver maximum benefits.
Many railway asset managers have therefore supplemented these traditional approaches by developing bespoke frameworks to meet the needs of their specific asset portfolio and stakeholder requirements (Karim et al., 2015; NRC, 2019), and there has been a growing transition to more value-driven approaches.

Value-based techniques attempted to measure a wider range of outcomes (not just cost) against the resources needed to deliver them; by not considering cost alone, it is easier to deliver benefits to a wider range of stakeholders. This paper explores the application of the management framework extended reliability, availability, maintainability and safety (ExRAMS) as introduced in the parallel paper by Litherland et al. (2021) as a value approach.

The ExRAMS framework presents ten parameters that are of key interest to railway infrastructure managers (IMs) and reflects the needs of the various different stakeholders with the aim of creating a single uniform approach. This paper demonstrates the application of the framework to a case study: the TransPennine Railway Corridor in England, UK. The paper explores how metrics can be calculated for each of the ten parameters using the typical data currently available to IMs. It identifies areas in which the data are still insufficient and incomplete, with the aim of informing future data collection. The final part of the paper explores how the parameters in the framework could form the bases of value analysis. 


\section{ExRAMS parameters}

As introduced in the parallel paper by Litherland et al. (2021), the ExRAMS framework comprises ten parameters arranged in a fourlevel structure, as shown in Figure 1. The hierarchy is based on the British standard BS EN 50126-1 (BSI, 2017). The lower level of the hierarchy comprises 'asset condition'; within this, two metrics are considered to measure the asset condition: 'condition and remaining life' and 'utilisation'. The next level of the hierarchy, 'asset performance', is a replicate of BS EN 50126-1 and contains 'reliability' and 'maintainability'. The second level of the hierarchy, 'service performance', contains 'environment' and 'train performance' alongside the traditional 'safety' and 'availability'. Levels 2, 3 and 4 of the hierarchy directly flow into one another; asset condition directly impacts asset performance, which consequently influences service performance. The top level 'service offering' contains high-level metrics for assessing performance: 'capacity' and 'capability and journey time'. These values are critical to railway IMs but are not necessarily directly influenced by the factors below. The top-level parameters are generally set at design stage or when a franchise or direct award is issued.

Railways are complex systems, and different stakeholders will have different requirements (Kilsby et al., 2017; Rama and Andrews, 2015; TLSG, 2012). The framework used to assess the operation of the railway will have maximum impact when all parameters are considered simultaneously. Considering one parameter alone could lead to false and incomplete conclusions being drawn.

To broaden the applications of the framework, the parameters were assessed at different levels of granularity. Parameters can be assessed at a very high level to understand the overall attributes of the railway, allowing benchmarking between different routes and between different railways. Parameters can also be assessed at a low level of granularity to distinguish the underlying causes of extreme or erroneous parameter values. Conversely, it allows for the determination of specific sections that are high performing, such that good practice can be replicated across a wider area of the network. The level of granularity used is largely determined by the data available and the requirements of the asset manager.

\section{Incorporating ExRAMS in the rail industry}

The ExRAMS framework is designed to consolidate the different approaches to RAMS analysis and facilitate a decision support tool (DST) that can aid asset managers' understanding of the current performance of their assets. The ExRAMS framework is not intended to facilitate a stand-alone tool but rather to serve as an integral component to a wider hierarchy of interlinking DSTs. It is the intention that the ExRAMS parameters can be used to support a value framework. A DST utilising the ExRAMS framework would be labelled as a 'diagnostic tool' as shown in Figure 2.

It is the authors' intention that during the implementation of the ExRAMS framework, all the data sets required are identified. These should be deposited into a data store that is used to drive the ExRAMS framework and other diagnostic tools, as well as any potential predictive and optimisation tools.

In future work, it is also intended that the framework serve as the basis for the development of 'predictive tools' and 'optimisation tools'. Predictive tools would enable asset managers to predict how the ExRAMS parameters evolve under different scenarios alongside other considerations such as whole-life-cycle costing. The optimisation tools would be developed to enable asset managers to determine the effectiveness of different asset-management strategies and to present and defend strategy decisions to stakeholders. This research will consider only the data store and ExRAMS diagnostic tool, as it is critical to understand fully the current operational status before attempting to make any predictions for the future.

\section{Implementation of the ExRAMS framework on the UK railway network}

This section will present an application of the ExRAMS framework. When using the framework to make decisions, it is critical to consider all the parameters. Considering only a subset may lead to

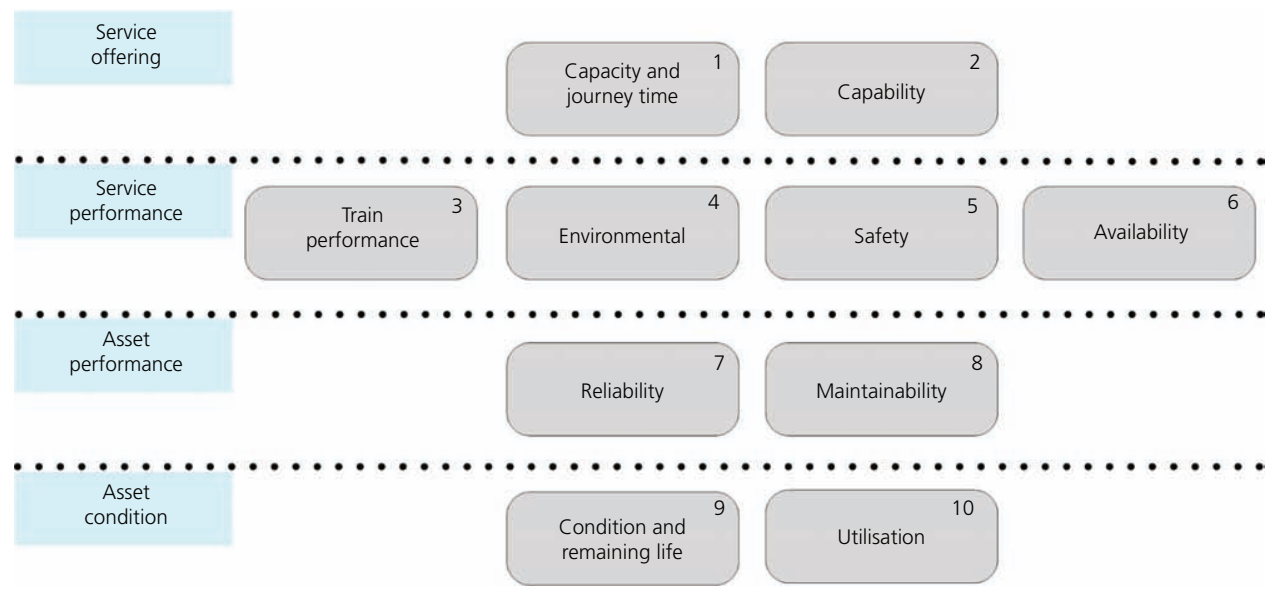

Figure 1. ExRAMS framework 


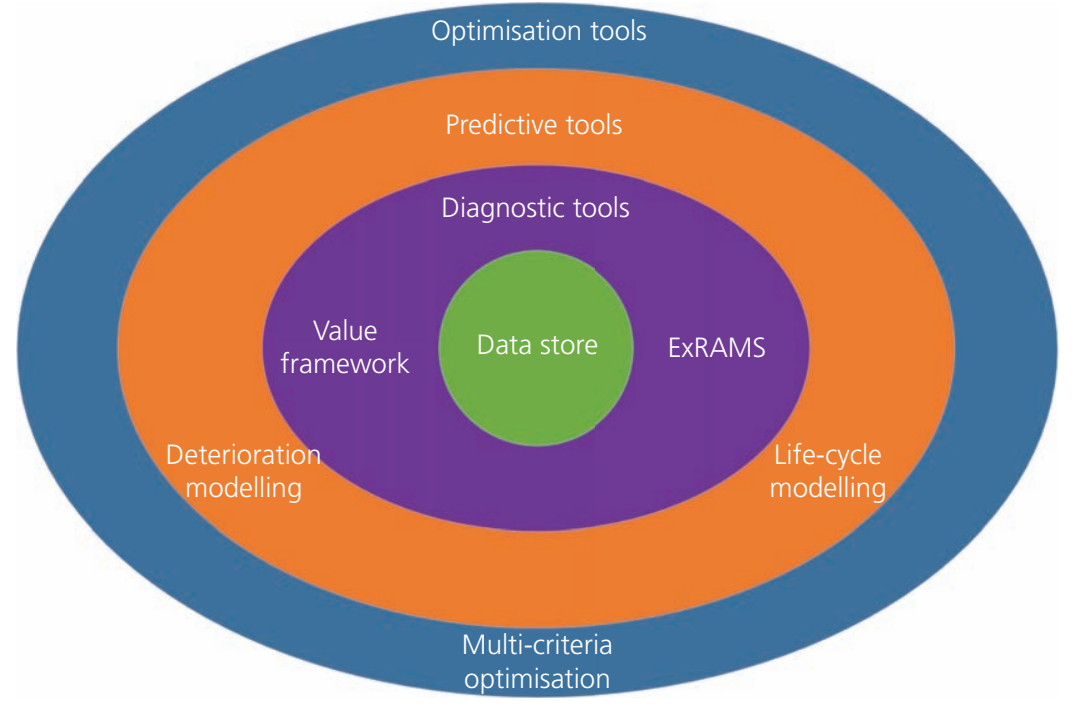

Figure 2. Hierarchy of DSTs

inaccurate conclusions being drawn. For example, a route with more traffic (greater utilisation) would be expected to have more failures (less reliable). Therefore, considering reliability only when making judgements can lead to poor decision-making.

A case study for the TransPennine Railway Corridor is used to demonstrate an implementation of the framework. The TransPennine Railway Corridor is a busy railway corridor in the north of England, UK (see Figure 3). It links three major UK cities: Manchester, Leeds and York.

The data used to calculate the parameters were taken from Network Rail's Decision Support Data Store (DSDS). The DSDS

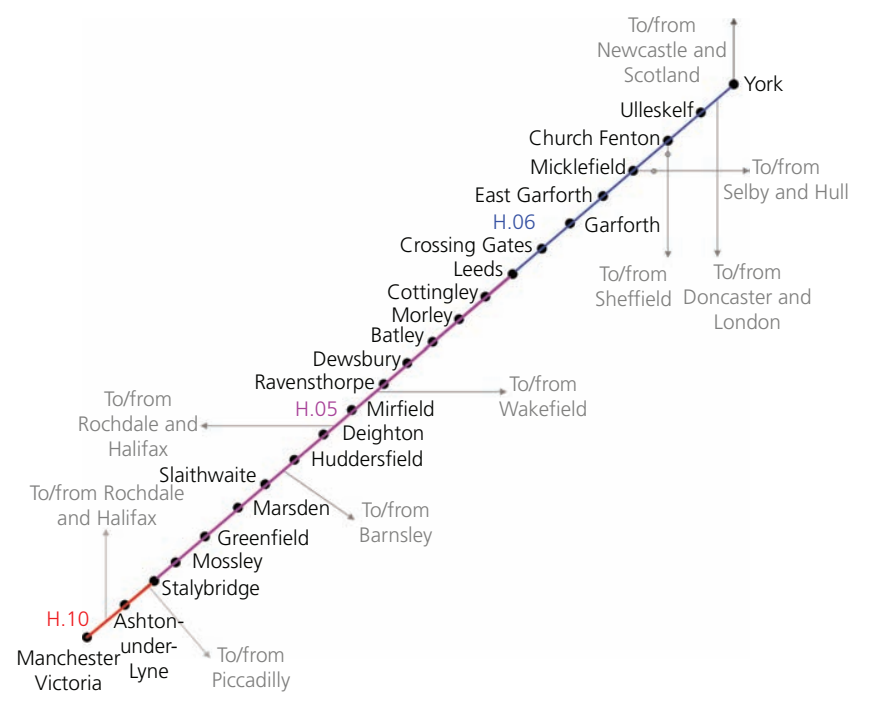

Figure 3. The TransPennine Railway Corridor contains a wide range of data sets, and when new data are deposited in the DSDS, the ExRAMS parameters can be updated.

For application in this study, it was decided that the parameters would be assessed at various levels of granularity as shown in Figure 4. These levels were selected based on Network Rail's division of the UK network. The highest level of granularity considered is 'network-wide' and considers the whole of the UK network. This level is useful for understanding the overall performance of the UK railway and allowing comparison with other networks should they use this framework in the future. However, considering parameters at a high level provides limited information on the factors that are influencing the metric scores. Network Rail considers the UK network as containing 14 'strategic routes' contained within five 'regions'. Assessing parameters at strategic route and regional levels again gives a very high-level view of the network, the main purpose of considering parameters at this level of granularity is to see how different parts of the network behave and identify differences between various sections of the UK railway.

Below the strategic route level, Network Rail has various other means to divide the network. However, they do not fit perfectly within a hierarchical structure and the boundaries between them can often overlap, unlike the boundaries between regions and routes. In this study, four intermediate levels of granularity will be considered: railway corridors such as the TransPennine Route, 'delivery units', 'strategic route sections' (SRSs) and 'Engineer's Line References’ (ELRs).

Each delivery unit is managed by a single infrastructure maintenance delivery manager (IMDM); most of the maintenance tasks are organised at the delivery unit level. SRSs run between key stations and junctions. ELRs are a legacy means of locating assets in the network; they can vary significantly in length. 


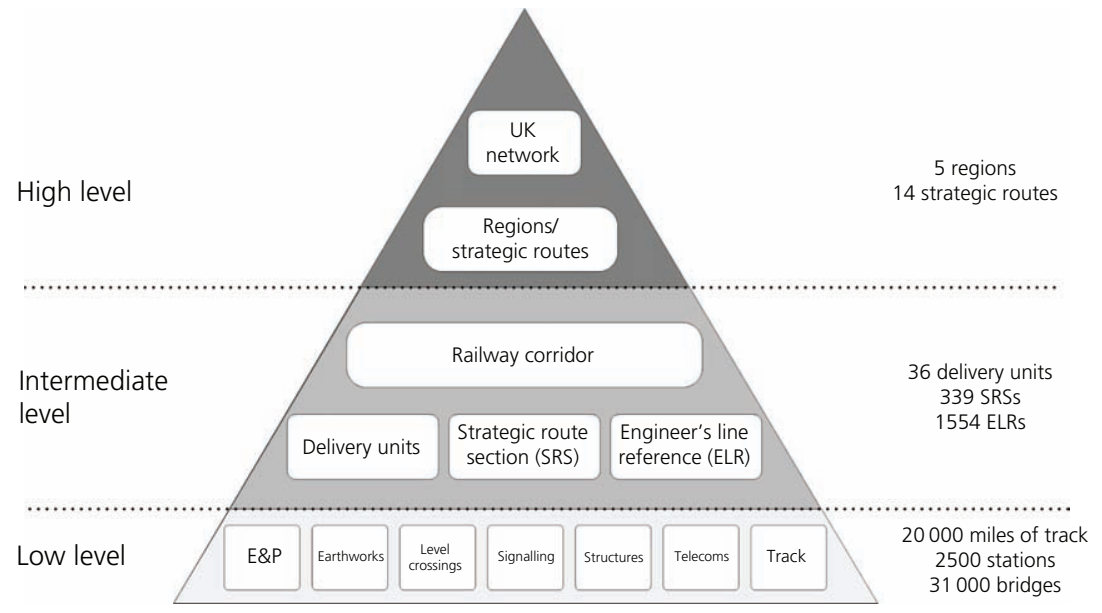

Figure 4. UK granularity levels. E\&P, electrification and power. 20000 miles $=3.22 \times 10^{4} \mathrm{~km}$

Assessing parameters at this level of granularity can highlight which parts of the network are limiting performance.

The lowest level of granularity is the asset level. Network Rail considers seven asset classes (within DSDS there are seven asset classes, but there are some assets, such as stations, that, at the time of writing, are not considered within DSDS):

- electrification and power (E\&P)

- earthworks including embankments, soil cuttings and rock cuttings

- level crossings

- signalling system

- structures including bridges, tunnels, retaining walls, culverts, footbridges and coastal, estuarine and river defences

- telecommunications

- track

Assessing parameters at this level can allow identification of specific assets that are limiting performance. The TransPennine Railway Corridor runs between the 'Eastern' and 'North West and Central' regions. The railway corridor spans three delivery units and contains three SRSs.

\section{Capacity}

\section{Metric results}

The calculation method for the theoretical maximum capacity presented by Litherland et al. (2021) was applied to the TransPennine Railway Corridor to determine a theoretical maximum, which was compared with the actual number of trains operated (prior to the timetable reduction due to the coronavirus pandemic).

Network Rail data were used to determine the position of signals along the railway corridor and the line speed. From this, the minimum separation time and hence the theoretical maximum number of trains per hour were calculated for the TransPennine
Railway Corridor. Timetable information was examined for each of the stations within the railway corridor to determine how many trains per hour currently pass through each station (both stopping and through trains). This value was expressed alongside the theoretical maximum value calculated, to allow comparison. It should be noted that the index presents a theoretical maximum capacity; the actual maximum capacity will be less than this, as the index does not account for

- extended and varied dwell times at stations

- variability in acceleration and decelerating rates

- trains travelling under the speed limit

[ 'recovery time'/'recovery capacity'.

The results are shown in Figure 5. The horizontal lines represent train paths, and the vertical lines represent stations. The dotted lines indicate trains that take a different path (not measured) for part of their journey and then rejoin the TransPennine Railway Corridor. The numbers above each vertical line indicate the number of trains per hour that currently pass through the station (in one direction). This value can be compared with the theoretical maximum shown above.

\section{Discussion}

It can be recognised that the section of the TransPennine Railway Corridor between Huddersfield and Mirfield is one of the most heavily trafficked parts of the railway corridor, with the number of passenger trains per hour alone currently close to the theoretical maximum of 14 trains per hour suggested by the metric. Due to the capacity constraints between Huddersfield and Mirfield, Network Rail is planning to increase the number of tracks from two to four over an 8 mile $(12.9 \mathrm{~km})$ section of the route as well as remodelling a number of stations.

It was found that the capacity between Leeds and York is limited to 13 trains per hour by a section of 1.5 miles $(2.41 \mathrm{~km})$ without a 


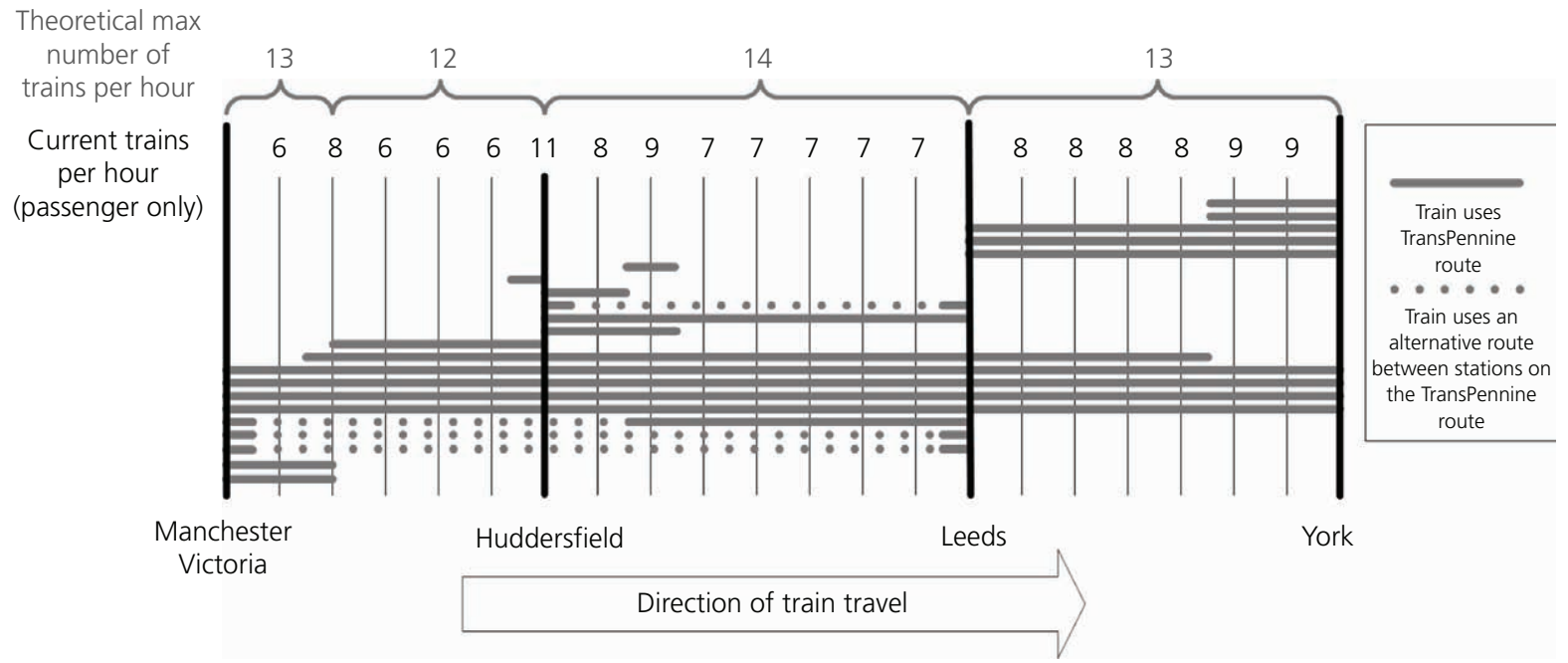

Figure 5. Capacity of the TransPennine Railway Corridor

signal. It should be noted that the capacity measure presented focuses on the number of trains alone; no consideration was given to the length or capacity of the trains that were operated.

\section{Capability and journey time}

\section{Metric results}

Network Rail's asset register enables the calculation of the capability metrics down to the lowest levels of granularity. However, there is limited benefit to expressing the values at this level, as the performance of the route will be limited by the weakest asset on the route. The operational specification for permissible traffic for the entire route will be limited by the capability of the weakest part of the route. For this reason, it was decided to express the capability parameters for the TransPennine Railway Corridor at the SRS level and railway corridor level. The metric results at the railway corridor level are shown in Table 1.

\section{Discussion}

A number of observations were made about the TransPennine Railway Corridor based on the capability parameter. For both the maximum axle load and maximum line speed, there is a significant difference between the minimum and lower quartile and only a small difference between the lower quartile and the mean, suggesting that only a small number of areas are limiting the maximum axle load and that increasing the speed limits on slower sections would have limited effect on the mean and overall journey times. It can also be noted that only the smallest freight loading gauges are permitted.

\section{Train performance}

\section{Punctuality metric assessment}

As introduced in the paper by Litherland et al. (2021), there are a wide range of performance metrics used across the rail sector to measure performance. Traditionally in the UK network, punctuality has been assessed using the public performance measure (PPM) and cancelled and significantly late (CaSL) metrics. These metrics are an assessment of the percentage of trains, in a given time period, that meet the required threshold. The metric is very flexible and can be used to express the punctuality of a given route right up to the national level. PPM has been used since 1997, and these data are available from the

Table 1. Capability: summary of capability metrics on the TransPennine Railway Corridor

\begin{tabular}{|c|c|c|c|c|c|c|c|c|c|}
\hline & Metric & & & & Calcula & d value & & & \\
\hline & & Min & Lower quartile & Mean & Median & Upper quartile & Max & & \\
\hline 1 & Maximum permitted axle loading: $t$ & 12 & 22 & 24 & 23 & 26 & 26 & & \\
\hline & & Min & Lower quartile & Mean & Median & Upper quartile & Max & & \\
\hline 2 & Maximum permitted speed: $\mathrm{mph}$ & 5 & 60 & 70 & 75 & 85 & 125 & & \\
\hline & & None & DC OLE & AC OLE & Third rail & Fourth rail & Combined & & \\
\hline 3 & Electrification: \% & 97.5 & 0 & 2.5 & 0 & 0 & 0 & & \\
\hline & & W6a & W7 & W8 & W9 Plus & W9 & W10 & W10a & W12 \\
\hline 4 & Loading gauge permitted & Y & $\mathrm{R}$ & $\mathrm{N}$ & $\mathrm{N}$ & $\mathrm{N}$ & $\mathrm{N}$ & $\mathrm{N}$ & $\mathrm{N}$ \\
\hline & & & Current ext & t (2019) & & Pred & ted extent $b$ & 2030 & \\
\hline 5 & ERTMS extent: \% & & 0 & & & & 0 & & \\
\hline
\end{tabular}

AC OLE, alternating-current overhead line equipment; DC OLE, direct-current overhead line equipment; ERTMS, European rail traffic management system; N, no; $R$, restricted; $Y$, yes 
Office of Rail and Road (ORR): Table 3114 - Public Performance Measure by Operator and Sector (Periodic) (ORR, 2020).

There are three train operating companies (TOCs) that use part (or all) of the TransPennine Railway Corridor: TransPennine Express, Arriva Trains Northern and Grand Central. The PPM and CaSL statistics from the first quarter of 2014-2015 until the third quarter of 2018-2019 are shown in Figures 6 and 7, respectively. Quarter 1 spans from 1 April until 30 June; quarter 2 spans from 1 July until 30 September; quarter 3 spans from 1 October until 31 December; and finally quarter 4 spans from 1 January until 31 March.

Like all metrics, these traditional metrics have their limitations; firstly, they are assessed over the whole route of the trains and do not allow finer details - for example, performance at certain stations. Also, PPM has a bias towards the terminating station, as only the time at this station is assessed, so there is a possibility to 'play the system' by leaving disproportionate contingency in the timetable at destination. To address these issues, a new assessment method has been introduced for use alongside PPM: the 'on time' metric, which expresses the percentage of trains that are less than $1 \mathrm{~min}$ late at a given station (or timing point). On time to 3, 5, 10 and 15 also record the number of trains on time to $3,5,10$ and $15 \mathrm{~min}$, respectively.

\section{Metric results: robustness}

The robustness metric is designed to express the ability of the network to cope with failures. Therefore, the robustness metric should be calculated at a high level of granularity. It would be possible to report the value at a lower level of granularity; however, the relationship between the robustness of a single component and the system robustness is complex. The robustness metric for the TransPennine Railway Corridor is therefore expressed at railway corridor level. Table 2 lists the number of delay minutes, the number of faults and the average number of delay minutes per asset failure for the TransPennine Railway Corridor, during Network Rail Control Period 5 (CP5) (1 April 2014 to 31 March 2019). The asset failures are divided into the seven asset classes discussed, to help identify which asset classes have the biggest effect. (Tracks have been subdivided into switches and crossings (S\&C) and plain-line tracks.)

\section{Discussion}

The PPM and CaSL match closely for TransPennine Express and Arriva Trains Northern, as they operate over similar areas, whereas Grand Central operates far fewer services over much longer distances. From the PPM statistics, it can be observed that the performance is consistently worse in the third quarter; this is likely to be caused by a higher volume of 'leaves on the line' delays and poorer weather conditions. It can be observed that 2018-2019 had some of the worst PPM scores and the highest number of CaSL trains.

It can also be observed that across the TransPennine Railway Corridor, although earthworks have the least number of failures

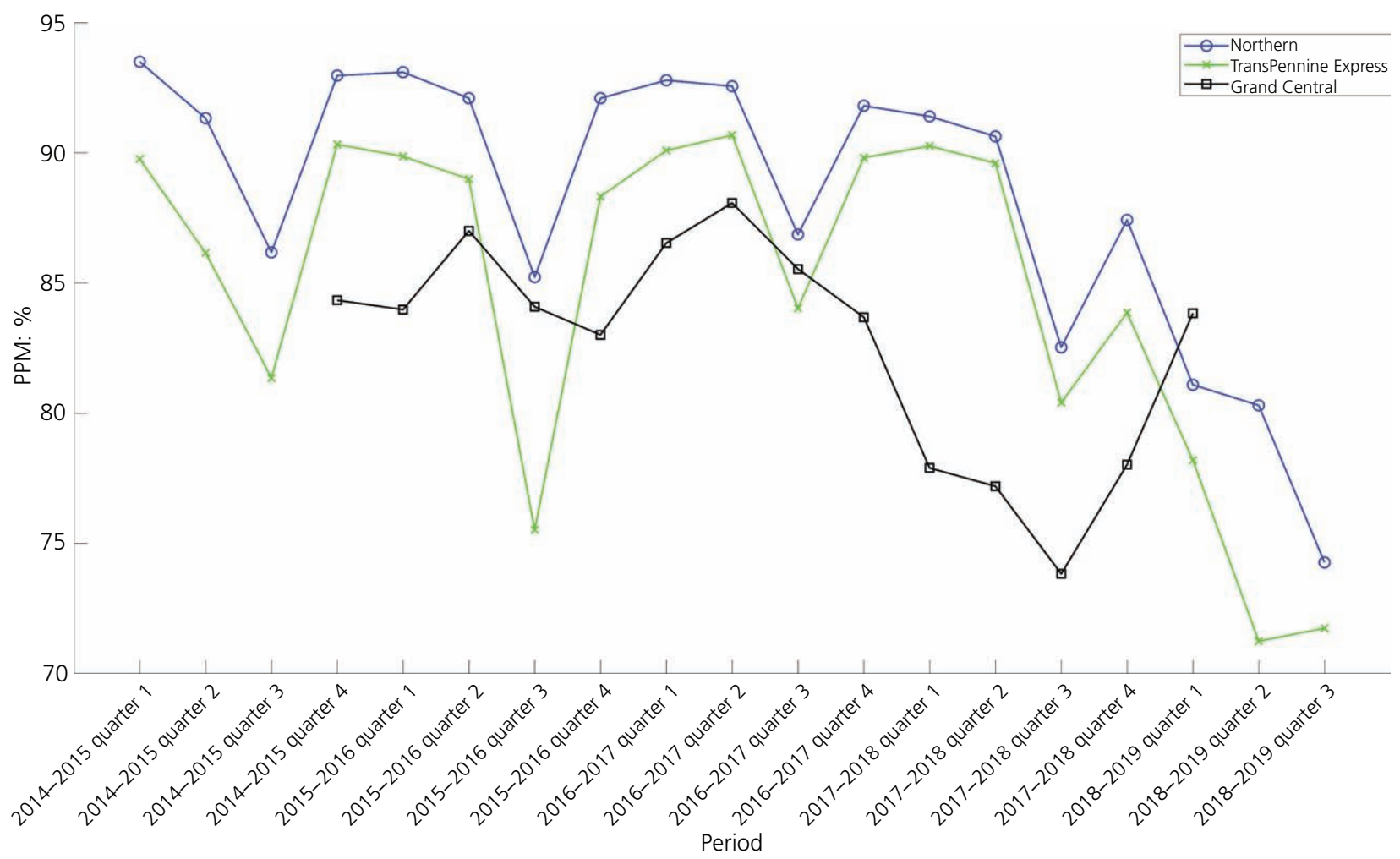

Figure 6. PPM TransPennine TOCs 


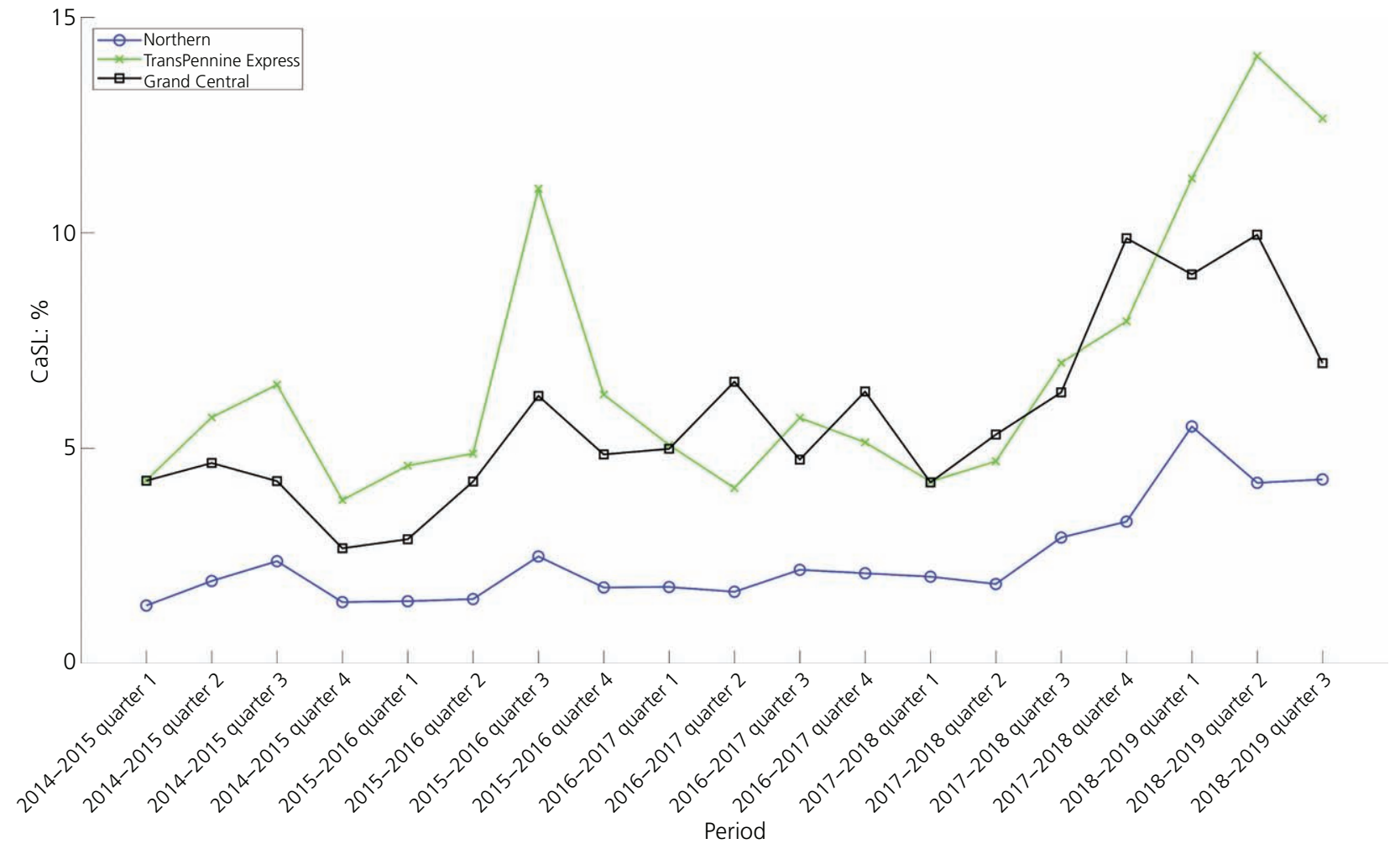

Figure 7. CaSL TransPennine TOCs

by a significant margin, earthwork failures have the highest average number of delay minutes per fault at $563.5 \mathrm{~min}$. This is likely due to the time required to resolve earthwork-related issues such as landslides being considerable. Structures also have a small number of failures but a significant number of delay minutes per failure at $255.1 \mathrm{~min}$, again likely caused by the significant amount of time required to rectify a structural failure.

\section{Environmental}

\section{Metric results}

It is important to understand the overall environmental performance of the network; it was decided to assess the environmental

Table 2. Train performance robustness: delay minutes per asset failure, TransPennine Railway Corridor, CP5

\begin{tabular}{|lrrc|} 
Asset class & $\begin{array}{c}\text { Delay } \\
\text { minutes }\end{array}$ & $\begin{array}{c}\text { Number } \\
\text { of faults }\end{array}$ & $\begin{array}{c}\text { Mean delay } \\
\text { minutes per } \\
\text { fault }\end{array}$ \\
\hline 1 E\&P & 14940 & 92 & 162.4 \\
2 Earthworks & 2254 & 4 & 563.5 \\
3 Level crossing & 11120 & 87 & 127.8 \\
4 Signal & 216675 & 1203 & 180.1 \\
5 Structures & 7142 & 28 & 255.1 \\
6 Telecommunications & 12866 & 157 & 81.9 \\
7 Track - plain line & 140259 & 558 & 251.4 \\
8 Track - S\&C & 74826 & 486 & 154.0 \\
Total & 480082 & 2615 & 183.6 \\
\hline
\end{tabular}

performance at the SRS and railway corridor levels. Currently, around 36\% (3583 miles $(5770 \mathrm{~km})$ ) of the UK network is electrified (ORR, 2018); however, there are a number of significant electrification projects ongoing in the 'Western' (Network Rail, 2019a) and 'East Midlands' (Network Rail, 2019b) strategic routes. About 3\% of the TransPennine Railway Corridor is electrified; this is concentrated in the area around the Leeds station.

The environmental performance metrics were determined for the whole TransPennine Railway Corridor using 2018-2019 data. Table 3 details the total passenger train $\mathrm{km}$ for each of the TOCs on the TransPennine Railway Corridor; this value is then restated

Table 3. Environmental: passenger train km for 2018-2019 on the TransPennine Railway Corridor by TOCs

\begin{tabular}{|lrrr|} 
TOC & $\begin{array}{c}\text { Total train } \\
\mathbf{k m}\end{array}$ & $\begin{array}{c}\text { Electric train } \\
\mathbf{k m}\end{array}$ & $\begin{array}{c}\text { Diesel train } \\
\mathbf{k m}\end{array}$ \\
\hline TOC 1 & 4912329 & 13040 & 4899289 \\
TOC 2 & 410880 & 0 & 410880 \\
TOC 3 & 147171 & 89150 & 58021 \\
TOC 4 & 9184 & 0 & 9184 \\
TOC 5 & 0 & 0 & 0 \\
TOC 6 & 83221 & 0 & 83221 \\
TOC 7 & 1371 & 0 & 1371 \\
TOC 8 & 5896010 & 146 & 5895864 \\
Miscellaneous & 30160 & 854 & 29306 \\
Total & 11490325 & 103190 & 11387135 \\
& & &
\end{tabular}


in terms of values for electric and diesel trains. TransPennine Express, Arriva Trains Northern and Grand Central make up 90\% of the traffic on the TransPennine Railway Corridor. The other TOCs use other SRSs that begin from Leeds, including the East Coast main line to London. Around $0.9 \%$ of passenger train $\mathrm{km}$ used electric traction.

Table 4 details the total freight train $\mathrm{km}$ for various types of freight on the TransPennine Railway Corridor. Freight makes up around $4 \%$ of the total train $\mathrm{km}$ on the TransPennine Railway Corridor; around $1.3 \%$ of freight traffic uses electric traction.

\section{Discussion}

The headline conclusion from this indicator is that very little traffic on the TransPennine Railway Corridor operates using electric traction. However, this is to be expected due to such a small percentage of the TransPennine Railway Corridor being electrified.

\section{Safety}

\section{Metric results}

The safety performance was expressed as the number of fatalities and weighted injuries (FWI) per year per $\mathrm{km}$. In the UK, the FWI index is used to express the overall safety risk. The FWI index is calculated by adding together all the fatalities and injuries that occur. The UK FWI value can be predicted based on the expected number of hazardous events and their frequency or determined directly based on information from safety incidents. In this study, the FWI was determined using the first method, as it allows the values to be calculated to a lower level of granularity. The FWI

Table 4. Environmental: freight train $\mathrm{km}$ for 2018-2019 on the TransPennine Railway Corridor by freight type

\begin{tabular}{|c|c|c|c|}
\hline Freight type & $\begin{array}{c}\text { Total train } \\
\text { km }\end{array}$ & $\begin{array}{l}\text { Electric train } \\
\text { km }\end{array}$ & $\begin{array}{c}\text { Diesel train } \\
\text { km }\end{array}$ \\
\hline Biomass & 157408 & 0 & 157408 \\
\hline Charter services & 939 & 25 & 914 \\
\hline Coal, ESI & 29212 & 0 & 29212 \\
\hline Coal, others & 4320 & 0 & 4320 \\
\hline $\begin{array}{l}\text { Construction } \\
\text { materials }\end{array}$ & 63766 & 1 & 63764 \\
\hline $\begin{array}{l}\text { Domestic } \\
\text { intermodal }\end{array}$ & 3383 & 473 & 2910 \\
\hline Domestic waste & 78560 & 0 & 78560 \\
\hline $\begin{array}{l}\text { Engineering } \\
\text { haulage }\end{array}$ & 57250 & 845 & 56405 \\
\hline Enterprise & 200 & 0 & 200 \\
\hline Industrial minerals & 3144 & 0 & 3144 \\
\hline Iron ore & 115 & 0 & 115 \\
\hline Petroleum & 14357 & 0 & 14357 \\
\hline $\begin{array}{l}\text { Postal } \\
\text { (parcel trains) }\end{array}$ & 1595 & 1569 & 26 \\
\hline Steel & 28982 & 0 & 28982 \\
\hline Others & 16300 & 3234 & 13066 \\
\hline Total & 459531 & 6148 & 453383 \\
\hline
\end{tabular}

ESI, electricity supply industry was calculated according to Equation 1, which was developed by the Rail Safety and Standards Board (RSSB, 2018) in their safety risk model and considers 118 hazardous events:

1. $\mathrm{FWI}=\sum_{i=1}^{118} \alpha_{i} E_{i} C_{i}$

where $\alpha_{i}$ is the scaling factor for the $i$ th hazardous event $E_{i}$ and $C_{i}$ is the FWI consequence of that event. At the UK network level, all the scaling factors are unity; at finer levels of granularity, reduced scaling factors are assumed based on 27 network attributes. Equation 1 was used to determine the FWI value for the three SRSs within the TransPennine Railway Corridor; the results are shown in Table 5. It should be noted that these values include suicides and attempted suicides.

\section{Discussion}

It can be seen across the three SRSs within the TransPennine Railway Corridor that there are a similar number of FWIs each year, varying between 1.7 and 2.2. However, the number of FWIs per $\mathrm{km}$ is considerably greater for SRS H.10, as it is much shorter than the other two SRSs. Looking at the breakdown of the contributors for the number of FWIs, it was found that suicides contributed the highest number of FWI, at around $80 \%$.

\section{Availability}

\section{Metric results}

Possession data from 2014 to 2017 were analysed to determine the availability metric. In total, there were 275992 possession records analysed. For the UK, it is assumed that there are 252 working days per year $(5 \times 52-8)), 52$ weekends per year and 365 nights per year. The possession data revealed that around $75 \%$ of possessions lasted less than $8 \mathrm{~h}$ and occurred at night. Around 25\% occurred at weekends and lasted between 8 and $56 \mathrm{~h}$. Less than $1 \%$ of possessions lasted more than $56 \mathrm{~h}$.

Breaking possession lengths down into smaller levels of granularity is problematic as each possession is in a different location (starts and ends at a different point) and possessions regularly extend across the boundaries between regions, delivery units, SRSs and ELRs. To allow a breakdown of the possessions, it was decided to focus only on the SRS that the possession started in. Table 6 summarises the availability for SRS H.05 on the TransPennine Railway Corridor.

Table 5. Safety: TransPennine Railway Corridor FWls per year by SRS

\begin{tabular}{|c|c|c|c|}
\hline $\begin{array}{l}\text { SRS } \\
\text { number }\end{array}$ & SRS name & $\begin{array}{l}\text { Total } \\
\text { FWIs/ } \\
\text { year }\end{array}$ & $\begin{array}{c}\text { (FWI/ } \\
\text { year)/ } \\
\text { km }\end{array}$ \\
\hline H.05 & Stalybridge-Leeds & 2.229 & 0.039 \\
\hline H.06 & Leeds-York & 1.730 & 0.053 \\
\hline H. 10 & $\begin{array}{l}\text { Manchester Victoria-Leeds by } \\
\text { way of Rochdale }\end{array}$ & 2.129 & 0.166 \\
\hline
\end{tabular}


An alternative approach to railway asset management value analysis: application

to a UK railway corridor

Litherland, Calvert, Andrews, Modhara and Kirwan
Table 6. Availability for SRS H.05

$\begin{array}{lrrrrc}\text { Type } & \mathbf{2 0 1 4} & \mathbf{2 0 1 5} & \mathbf{2 0 1 6} & \text { Average } & \text { Availability: \% } \\ \text { Working day } & 252 & 251 & 252 & 251.67 & 99.87 \\ \text { Weekend } & 38 & 34 & 23 & 31.66 & 60.90 \\ \text { Night } & 296 & 263 & 295 & 284.7 & 77.99\end{array}$

The metric was based on the average values for 2014, 2015 and 2016. There were no possessions of more than $56 \mathrm{~h}$ recorded on the TransPennine Railway Corridor.

\section{Discussion}

It can be seen that for SRS H.05, the working day availability is at $99.9 \%$, with just one possession occurring during a working day in the 3-year interval. The weekend availability is around $60 \%$, with a possession taking place around 20 weekends a year. This value was likely to be higher than normal due to upgrade works currently being undertaken on the TransPennine Railway Corridor (Network Rail, 2019c). It should be noted that possessions do not take into account disruption caused by failures and unplanned possessions. This is considered in the reliability metric. The exception to this is when the disruption caused by a failure extends beyond the end of service on the day on which the fault occurred. If the disruption extends into the second day, then it becomes a 'planned' possession and will be counted within the possession data set and will be captured within this metric.

\section{Reliability}

\section{Metric results}

The number of service-affecting failures (SAFs) for the TransPennine Railway Corridor was determined using the Network Rail reliability tool. The tool records the fault description, fault location and number of delay minutes per asset failure. The faults were grouped into the seven asset classes discussed previously.

As the location of the fault was known, it was possible to calculate the reliability at any level of granularity. It was decided that the most appropriate levels of granularity to report reliability at were ELR, SRS and railway corridor level. Table 7 summarises the two reliability metrics, the number of SAFs and mean time between SAFs (MTBSAFs), for the entire TransPennine Railway Corridor for CP5.

Table 7. Reliability: SAFs and MTBSAFs for the TransPennine Railway Corridor, CP5

\begin{tabular}{|c|c|c|c|}
\hline & Asset class & Number of SAFs & MTBSAFs \\
\hline 1 & $E \& P$ & 92 & 19.85 \\
\hline 2 & Earthworks & 4 & 456.5 \\
\hline 3 & Level crossing & 87 & 20.99 \\
\hline 4 & Signal & 1203 & 1.518 \\
\hline 5 & Structures & 28 & 65.18 \\
\hline 6 & Telecommunications & 157 & 11.63 \\
\hline \multirow[t]{2}{*}{7} & Track & 1044 & 1.752 \\
\hline & Total & 2615 & 0.698 \\
\hline
\end{tabular}

\section{Discussion}

It can be observed that earthworks and structures caused the smallest number of SAFs, with earthwork failures in particular being extremely rare. In contrast, the track and signalling system caused a significant number of SAFs, with over 1000 reported in each discipline. Hence, reliability improvements should focus on the track and signalling system.

\section{Maintainability}

\section{Metric results}

Maintenance records within the DSDS were analysed to determine the number of hours spent on various maintenance tasks and the volume of maintenance performed between April 2009 and April 2018. As maintenance tasks are normally organised at the delivery unit level, it was decided to group the maintenance by delivery unit. A delivery unit is managed by a single IMDM, who is responsible for all the maintenance in the delivery unit. The TransPennine Railway Corridor spans three delivery units: Leeds, Manchester and York.

On analysis of the records, it became apparent that determining the total volume of work performed was difficult, as different maintenance tasks had different units of volume. For example, track maintenance such as tamping was assessed in $\mathrm{km}$, whereas sleeper replacements were assessed by the number of sleepers replaced. The only meaningful way to express the volume of maintenance would be to report on each of the work tasks individually. However, as there were several thousand individual work tasks, it was considered that expressing this information in the ExRAMS framework would not be useful to IMs. However, the data are still available in the data store.

It was therefore decided to report only on the hours of work completed within the ExRAMS framework. Maintenance records were examined to determine the number of hours spent on maintenance in three disciplines: track, signalling and E\&P. The data were in such a format that it was difficult to extract further disciplines without significant data manipulation. For the York delivery unit, E\&P data were not available. For the signalling discipline, it was observed that there were a very small number of records that had an uncharacteristically large completion time; it was speculated that these entries were inaccurate. To verify this, these records were inspected. It was found that in all the uncharacteristic records, work was being performed only on a single asset and that other work of the same type had an average completion time several orders of magnitude smaller. Based on this, it was concluded that these records were incorrect and all records with a completion time over $100 \mathrm{~h}$ were not used. In the Leeds delivery unit, this filter resulted in 70 records being removed out of 380370 .

Figure 8 shows the results of the maintainability analysis. It can be seen that in all three cases, track was the discipline that received the most hours. Expressing only the total number of hours of maintenance limits the versatility of the maintainability parameter, 

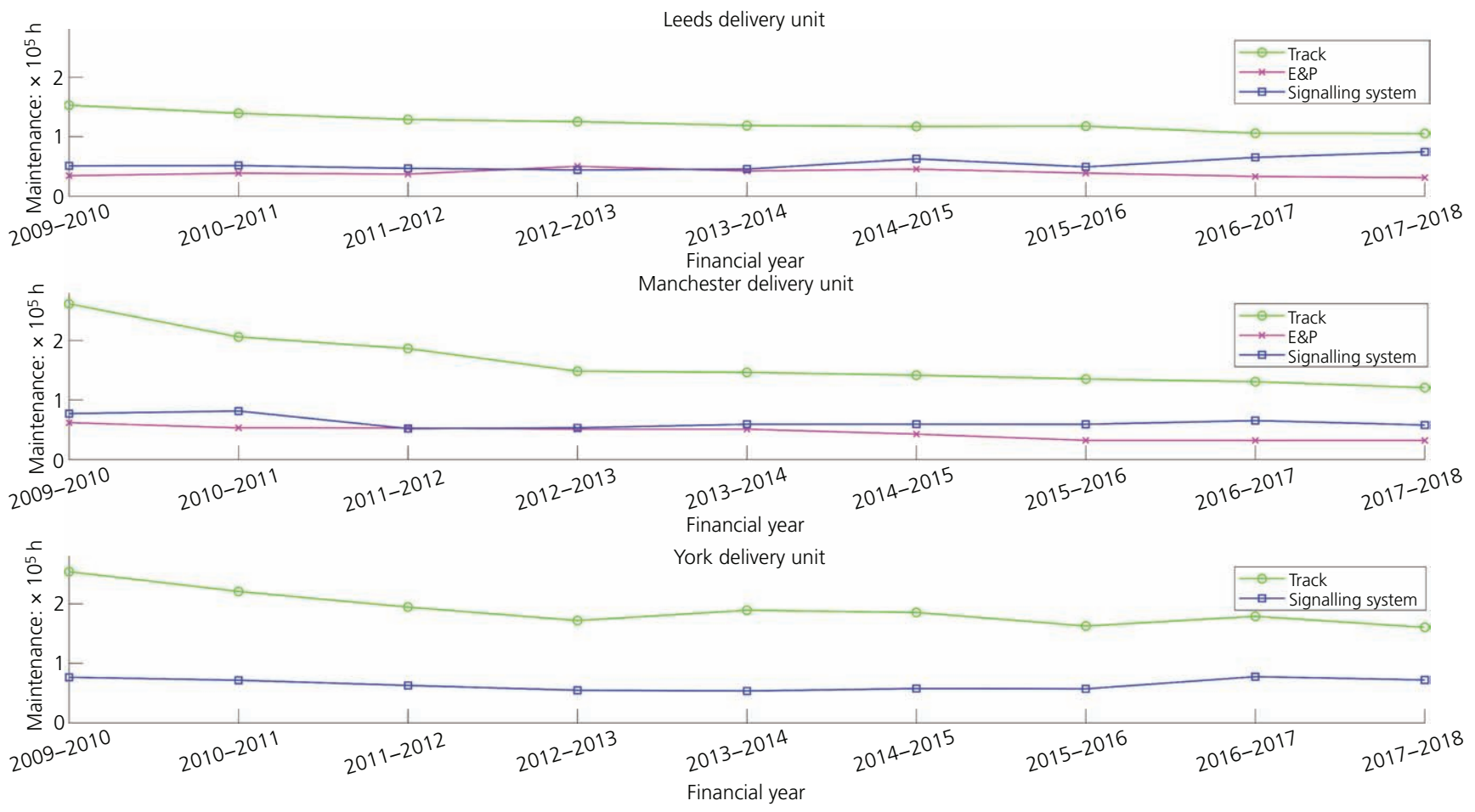

Figure 8. Hours of maintenance of TransPennine delivery units

as it will show only the total number of hours of maintenance completed and allows comparison only of the overall number of hours. It cannot provide insight into why the hours of maintenance might be changing. This information might be gleaned from the other parameters within the framework. If the IM does wish to see the volume of each of the different maintenance tasks, then these data can be obtained from the data store.

\section{Discussion}

The results of the metric show that overall, the hours of track maintenance were decreasing between 2010 and 2018, whereas the hours of signalling and E\&P maintenance were increasing. It was not entirely clear the reason for this, as it was not possible to express the volume of maintenance performed, due to different tasks having different units of volume.

\section{Condition and remaining life}

\section{Metric results}

The replacement value of Network Rail's inventory is determined by the ORR using engineering judgement to attribute the cost to replace assets. The values at strategic route and regional levels are apportioned from the total. The residual value is estimated based on the current age and condition of the assets. The difference between these can then be used to determine the percentage of life remaining. Note that different assets have different service lives, so the asset with the smallest remaining value may not necessarily be the one that becomes service life expired first.
Network Rail assesses the residual value at the start of each CP and then assesses the residual value at the end of each subsequent year in that CP. These values are compared with the value at the start of the CP so the change in the residual value can be assessed. Table 8 shows the ORR assessment of the replacement values of all the assets on the UK network as well as Network Rail's assessment of their current (April 2019) residual value. The percentage remaining value (the difference between these) is shown in the final column.

\section{Discussion}

The end of CP5 assessment shows that overall, the UK railway has around $50 \%$ of its life remaining, with the current value of assets a little over $50 \%$ of the replacement value of the network. The assets in the poorest condition are structures (bridges) and sleepers, with more than $60 \%$ of their value lost. The newest assets are earthworks and drainage, with only around $25 \%$ of their value lost. It is interesting to note that despite structures having one of the biggest percentages of value lost, they are still the most valuable asset class.

\section{Utilisation}

\section{Metric results}

For the application to the TransPennine Railway Corridor, the number of trains that use it, and hence the utilisation, was assessed based on equivalent million gross tonnes per annum (EMGTPA). The EMGTPA metric was expressed at both railway corridor level and SRS level. Although it is possible to calculate 
Table 8. Condition and remaining life: Great Britain network replacement and residual values and percentage life used

\begin{tabular}{llccc} 
Asset class & \multicolumn{1}{c}{ Subclass } & $\begin{array}{c}\text { Replacement value: } \\
\text { f billions }\end{array}$ & $\begin{array}{c}\text { Residual value (2019): } \\
\text { f billions }\end{array}$ & $\begin{array}{c}\text { Percentage value } \\
\text { remaining: \% }\end{array}$ \\
\hline Track & Rail & 8.48 & 3.93 & 46.3 \\
Track & S\&C & 5.20 & 2.47 & 47.5 \\
Track & Sleepers & 6.31 & 2.15 & 34.0 \\
Track & Ballast & 6.87 & 3.32 & 48.3 \\
Signalling & All & 15.40 & 6.57 & 42.6 \\
Telecommunication & All & 1.10 & 0.52 & 46.9 \\
E\&P & Conductor rail & 1.22 & 0.81 & 66.3 \\
E\&P & Overhead line equipment & 13.98 & 7.75 & 55.4 \\
Buildings & Stations & 7.10 & 3.87 & 54.5 \\
Buildings & Light maintenance depot & 0.70 & 0.37 & 55.3 \\
Structures & Major deck elements (PLBE) & 130.28 & 48.58 & 37.2 \\
Structures & Tunnel condition & 17.75 & 7.95 & 44.8 \\
Earthworks & All & 57.50 & 43.52 & 75.6 \\
Drainage & Track drainage & 1.03 & 0.77 & 74.3 \\
Drainage & Earthworks and structures drainage & 0.60 & 0.46 & 75.9 \\
Total & All & 273.50 & 133.00 & 51.4
\end{tabular}

PLBE, principal load-bearing element

to a lower level, there is limited benefit to doing this, as the EMGTPA value can change significantly only at junctions. The metric reports the minimum, maximum and average EMGTPA. The minimum value allows more minor routes such as regional lines to be identified, whereas the maximum value allows the lines most heavily used to be identified.

The EMGTPA was calculated in a similar way to the maximum speed and maximum axle load in the capability metric; the EMGTPA for each section reported was scaled based on the length of the section. For the TransPennine Railway Corridor, the minimum is 0 EMGTPA, the average is 8.18 EMGTPA and the maximum value is 20.3 EMGTPA.

\section{Discussion}

It can be seen that the smallest EMGTPA value is 0; this suggests that somewhere on the railway corridor, there are lines that are no longer trafficked. Analysis revealed that less than $0.1 \%$ of the TransPennine Railway Corridor is recorded as having 0 EMGTPA per year. The average value for the TransPennine Railway Corridor is close to the UK average value of 8 EMGTPA.

\section{Value frameworks and value function}

The previous section has demonstrated a means of calculating metrics to determine the achievement for each parameter within the ExRAMS framework, as well as highlighting areas where additional data are required. Nonetheless, it can still be difficult to draw conclusions between the parameters, as they are measured using different units. For example, which is more beneficial, a $1 \%$ increase in availability or a decrease of ten delay minutes per failure? The answer to this very much depends on what one is trying to achieve, which is where a value approach can be beneficial. The final part of this paper looks at how the parameter within the ExRAMS framework can be used to express value.
Value analysis is about using assets to deliver value and achieve the organisation's objectives. To realise value, there must be a focus on balancing cost, risk and performance rather than focusing on cost alone (IAM, 2015; Srinivasan and Parlikad, 2017).

It is common practice to use a value framework as a means of expressing and quantifying a company's key values based on their objectives. A value framework defines the measurement points that are important to the organisation and in delivering the company's organisational objectives (Boers, 2019). A metric similar to the one in the paper can be seen in value frameworks across industries, including the health care sector (NHS, 2017), nuclear industry (NDA, 2016) and transport industry (Mihai, 2019), as well as in the rail industry (Algaard and Lines, 2020; Papathanasiou et al., 2020; Rangarajan et al., 2013).

Within a value framework, typically all metrics are converted onto a common scale. One of the most common choices is cost; monetised weightings can be assigned to each metric, allowing them to be expressed against a common monetary base. The output of each is then fed into a value function or similar. An example value equation is shown in Figure 9. The value function translates the performance in each area into an overall expression of value, with the aim of demonstrating how a given strategy delivers against the organisation's overall objectives.

One of the difficulties in creating a value framework is that there is no set methodology to translate the metrics for each of the different parameters onto a common scale and many approaches to this can often be subjective with no substantial analysis behind the values. As discussed, the ExRAMS framework is not designed to be a stand-alone tool, and as future work, the authors plan to explore how the ExRAMS parameters can be used to support a value framework. 


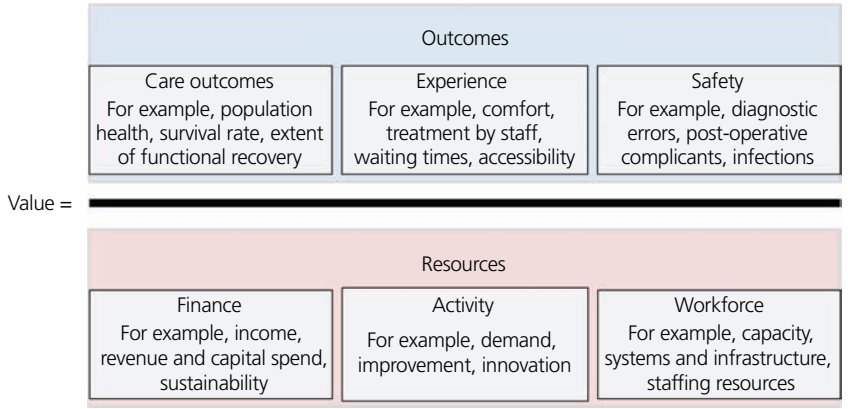

Figure 9. Value equation (NHS, 2017)

\section{Conclusion}

A railway network is a complex system comprising many asset disciplines with a large number of stakeholders. Each stakeholder has their own priorities and interests; therefore, having an effective asset-management framework that can assess all of their needs is extremely challenging. Consequently, railway asset managers have tended to conduct analysis on an a bespoke basis basis, based on the requirements of the key stakeholders at the time. This generally does not deliver the best value for the IM and makes comparing between analysis impossible. This paper presents the application of an ExRAMS framework defined specifically for railway infrastructure. The framework is designed to consolidate the various approaches to RAMS in the railway industry into one single approach that can fulfil the needs of all railway IMs and can deliver the maximum value for the organisation and explores how the parameters within the ExRAMS could be used within a value analysis.

It was found that in general, the data sets currently available to asset managers are sufficient to assess the metrics present within the ExRAMS framework, and at least one metric was calculated for each of the parameters. Nonetheless, the data sets for some attributes - for example, train performance and safety - are considerably more advanced than others - for example, environmental and remaining life.

As future work, the authors plan to develop the value analysis using the ExRAMS parameters as well as explore the interactions between the parameters in enhanced detail.

\section{Acknowledgements}

John Andrews is the Royal Academy of Engineering and Network Rail Professor of Infrastructure Asset Management. He is also the director of the Lloyd's Register Foundation Resilience Engineering Research Group at the University of Nottingham. Jack Litherland is a research fellow in railway infrastructure asset management. Gareth Calvert is a PhD student at the University of Nottingham. This work was supported by the Engineering and Physical Sciences Research Council (EP/N50970X/1). Additional support was received from Network Rail. Sunny Modhara is a whole lifecycle costing manager at Network Rail, and Andy
Kirwan is the head of Advanced Analytics at Network Rail. They gratefully acknowledge the support of these organisations.

\section{REFERENCES}

Algaard EM and Lines RD (2020) Railway infrastructure portfolio management in the UK. Infrastructure Asset Management 7(1): 15-24, https://doi.org/10.1680/jinam.18.00012.

Boers D (2019) Creating a value-framework to mazimise sustainable return. The Asset Journal 13(4): 22-27.

BSI (2017) BS EN 50126-1:2017: Railway applications. The specification and demonstration of reliability, availability, maintainability and safety (RAMS). Generic RAMS process. BSI, London, UK.

Fabrycky WJ and Blanchard SB (1991) Life-cycle Cost and Economic Analysis. Prentice Hall, Englewood Cliffs, NJ, USA.

Farr JV and Faber I (2018) Engineering Economics of Life Cycle Cost Analysis. CRC Press, Boca Raton, FL, USA.

IAM (Institute of Asset Management) (2015) Asset Management - An Anatomy, Version 3. IAM, Bristol, UK.

Karim R, Jagare V, Lindberg L and Kumar U (2015) Robust and Reliable Transport System (RTS) - A Strategic Agenda for Resource Pooling, Collaboration, Innovation and Research. Luleå University of Technology, Luleå, Sweden. See https://www.ltu.se/cms_fs/1.129828!/ file/RTS 2015 webb.pdf (accessed 18/02/2021).

Kilsby P, Remenyte-Prescott R and Andrews J (2017) A modelling approach for railway overhead line equipment asset management. Reliability Engineering and System Safety 168: 326-337, https://doi. org/10.1016/j.ress.2017.02.012.

Litherland J, Calvert G, Andrews J, Modhara S and Kirwan A (2021) An alternative approach to railway asset management value analysis: framework development. Infrastructure Asset Management, https://doi. $\operatorname{org} / 10.1680 /$ jinam.20.00002. [Submitted].

Mahboob Q and Zio E (eds) (2018) Handbook of RAMS in Railway Systems: Theory and Practice. CRC Press, Boca Raton, FL, USA.

Mihai F (2019) The assessment of long term investment needs for Western Australia's State Road Needs. The Asset Journal 13(4): 4-12.

NDA (Nuclear Decommissioning Authority) (2016) The NDA Value Framework, Version 1.2. NDA, Moor Row, UK. See https://assets. publishing.service.gov.uk/government/uploads/system/uploads/ attachment_data/file/489312/NDA_Value_Framework_Version_1.2.pdf (accessed 18/02/2021).

Network Rail (2019a) Modernising the Great Western Route. Network Rail, London, UK. See https://www.networkrail.co.uk/running-the-railway/ourroutes/western/great-western-mainline/ (accessed 20/01/2020).

Network Rail (2019b) Midland Main Line Upgrade. Network Rail, London, UK. See https://www.networkrail.co.uk/running-the-railway/our-routes/ east-midlands/midland-main-line-upgrade/ (accessed 18/02/2021).

Network Rail (2019c) Network Rail: Transpennine Upgrade. Network Rail, London, UK. See https://www.networkrail.co.uk/running-therailway/railway-upgrade-plan/key-projects/transpennine-route-upgrade/ (accessed 18/02/2021).

NHS (National Health Service) (2017) Decision Framework: A Reference Guide for Organisations Making Value-based Decisions for Healthcare Services. NHS, London, UK. See https://www. futurefocusedfinance.nhs.uk/sites/default/files/BPV\%20Decision $\%$ 20Framework\%200617.pdf (accessed 18/02/2021).

NRC (Network Rail Consulting) (2019) Systems Analysis. NRC, London, UK. See https://www.networkrailconsulting.com/news-andpublications/publications/systems-analysis/ (accessed 18/02/2021).

ORR (Office of Road and Rail) (2018) Rail Infrastructure, Assets and Environmental 2017-18 Annual Statistical Release. ORR, London, UK.

ORR (2020) Table 3114 - Public Performance Measure by Operator and Sector (Periodic). ORR, London, UK. See https://dataportal.orr.gov. uk/statistics/performance/passenger-rail-performance/table-3114public-performance-measure-by-operator-and-sector-periodic/ (accessed 18/02/2021). 
Papathanasiou N, Adey BT and Burkhalter M (2020) Defining and quantifying railway service to plan infrastructure interventions. Infrastructure Asset Management 7(3): 146-166, https://doi.org/10. 1680/jinam.18.00044.

Rama D and Andrews JD (2015) A holistic modelling framework for railway infrastructure asset management. International Journal of Performability Engineering 11(2): 107-120.

Rangarajan K, Long S, Tobias A and Keister M (2013) The role of stakeholder engagement in the development of sustainable rail infrastructure systems. Research in Transportation Business \& Management 7: 106-113, https://doi.org/10.1016/j.rtbm.2013. 03.007 .
RSSB (Rail Safety and Standards Board) (2018) RSSB Rail Risk Portal. RSSB, London, UK. See https://catalogues.rssb.co.uk/rail-risk-portal (accessed 18/02/2021).

Srinivasan R and Parlikad AK (2017) An approach to value-based infrastructure asset management. Infrastructure Asset Management 4(3): 87-95, https://doi.org/10.1680/jinam.17.00003.

TSLG (Technical Strategy Leadership Group) (2012) Rail Technical Strategy. RSSB, London, UK.

Vandoorne R and Gräbe PJ (2018) Stochastic rail life cycle cost maintenance modelling using Monte Carlo simulation. Proceedings of the Institution of Mechanical Engineers, Part F: Journal of Rail and Rapid Transit 232(4): 1240-1251, https://doi.org/10.1177/0954409717714645.

\section{How can you contribute?}

To discuss this paper, please submit up to 500 words to the editor at journals@ice.org.uk. Your contribution will be forwarded to the author(s) for a reply and, if considered appropriate by the editorial board, it will be published as a discussion in a future issue of the journal. 